\title{
The co-production of value in an art market - exploring service relationships
}

\author{
Erik A. Borg, Lars Vigerland \\ Södertörn University, Alfred Nobels Alle 9, 14189 Huddinge, Sweden \\ Email address: \\ erik.borg@sh.se(Erik A. Borg), lars.vigerland@sh.se(Lars Vigerland)
}

\section{To cite this article:}

Erik A. Borg, Lars Vigerland. The Co-Production of Value in an Art Market: Exploring Service Relationships, Journal of Investment and Management. Vol. 2, No. 3, 2013, pp. 57-69. doi: 10.11648/j.jim.20130203.14

\begin{abstract}
The purpose of this research is to analyze service dominated relationships and differences in characteristics of these relationships within arts marketing. The appreciation of art is seen as a service and is intertwined with the creation of company identity and thus a subtle kind of marketing, whether this is a conscious or non-conscious strategy from a company perspective. Companies invest in art in order to enhance their image, and establish network relationship with art firms. The data is collected from the Swedish non-profit art market of public and private organizations with focus on Stockholm, an art market place as well as a prime site for company head quarters. The data is analyzed with multivariate correspondence analysis (MCA), which is also known as geometric data analysis (GDA). This method enables analysis of relationships as well as overall characteristics of the participants in these relationships: a part of service as well as a creation of company identity, thus marketing. The research has shown that the service encounter within arts is enhanced within relationships between key actors that can be considered co-producers of art and that multivariate correspondence analysis is a helpful tool to identify these relationships and company characteristics in a structured manner. The methodology is generating visual pictures of the art market that cooperates with profit making ordinary companies in different industries. The graph that is produced with MCA is a visualization of what can be regarded as a map of the companies with connections to the nonprofit art market, whether these connections are formal and a part of regular business activities or informal and relatively weak.
\end{abstract}

Keywords: Arts Marketing, Co-Creation, Multiple Correspondence Analysis, Customer Value, Nordic School, Relationships, Networks, Service Dominant Logic

\section{Introduction}

The appreciation of art can be viewed as a co-production involving the artist, galleries, art investors, art collectors, museums and several other nonprofit actors in the art market. Artists and organizations that create and communicate art can be surrounded by a network or engaged in relationships which influence the appreciated value of art. When mapping these networks or relationships by using multivariate correspondence analysis (MCA), the dynamics of an art market can be analyzed. Relationships can be regarded as conceptually and basically similar to networks, although relationships are less multidimensional. A network perspective of arts marketing can be associated with a recent development of marketing theory, that is closely linked with the introduction of the service dominant logic of marketing. The value of art is co-produced in the interface between those who make, communicate, supply and appreciate art. Art can be viewed as a service and arts marketing as a form of service marketing, where the characteristics of the company and the kind of relationships the company has is of vital importance on the impression it makes on other organizations on the market or in the line of business in question. In this way any organization creates a company identity via characteristics associated to the company in question and thus marketing itself. Through distinctive company characteristics, companies can distinguish themselves from each other, as a way or strategy of market differentiation. These unique characteristics may well be part of a conscious strategy, or more a seemingly coincidental occurrence. Any action or company characteristic stems however most certainly from an established company culture and occurs only to a small degree by pure chance. Through the use of multiple correspondence analysis, the relationships between the different actors and the type of relationships in the art 
market can be identified, displayed and analyzed.

We have analyzed networks made up by non-profit art organizations such as museums, galleries, art schools, theatres, operas on one hand and profit maximizing firms using art to augment the service they are providing to customers on the other hand. Art, in different forms, is appreciated when there is an interaction between those who make art, those who invest in art, those who communicate art and those who supply art and those who appreciate art. Art is appreciated as a service in co-producing networks or relationships. We have applied a method called multiple correspondence analysis, which is a multivariate statistical method, to create clusters or polarities of common or distinctive characteristics and to discover relationships between the art market and companies of different line of business that are profit oriented. It is when different actors in art networks interact that art can gain a significant and appreciated customer value. Art that remains in the studio of the artist or in the depository of a museum, and is not appreciated by an audience, does not have a market value. Galleries, museums, theatres, art investors, private or corporate art collectors and the audience interact to give art its value. This value, whether the role on the market is that of the collector or the provider, can be regarded as an extension of a corporate identity, and thus a part of a marketing scheme.

\section{The Service Dominant Logic}

The marketing discipline has gone through a distinctive development following the introduction of the service dominant logic (S-D logic). The service dominant logic represents the introduction of a theoretical framework for analysis that emphasizes the co-creation of value, intangible resources and network relationships. Much of marketing theory has been developed within a product dominant logic - the (P-D) logic. Products have been viewed as having value in itself regardless of what service can be gained from a product. The service dominant logic can be traced to the early days of economic theory. The new (S-D) logic has evolved from research appearing over the last four decades (Vargo and Lush 2004, 2008: Lusch and Vargo 2006; Vargo and Archpru Akaka 2009; Ballantyne and Varey 2008; Gummesson 2008). The (S-D) logic contrasts the traditional (P-D) logic in several ways. The (S-D) logic points to network relationships and does not make a sharp distinction between products and services. Within the traditional (P-D) logic, marketing is analyzed from a producer and product perspective where the objective of the marketer was to achieve an exchange with the customer. The new (S-D) logic has several advantages in capturing a consumer perspective by looking at what is offered in a market as a service which generates value to the customer. The new logic identifies core competences that can evolve to competitive advantage. It furthermore identifies potential customers that can benefit from these advantages. Compelling value propositions can evolve, and feedback from the marketplace can improve the firm's performance (Vargo and Lush 2004). Companies are developing competitive advantages through the use of alternative business and marketing strategies reflecting the resource advantages of the firm (Hunt 2010).

\section{Networks and co-Creation of Value}

The service encounter can be analyzed with the use of network theory. Network theory has originally been developed to analyze business to business markets but has a wider relevance to marketing at large (Mattsson and Johansson 2006; Batt and Purchase 2004; Borg 1991, 2001, 2009; Rao et al. 2008). Companies build networks with customers and with other firms. The value in the service relationships appear through interaction. A company form links and bonds to provide superior value. Competitive advantage is achieved within the reams of interactive business relationships. Network theory has evolved over time and has had business to business relationships as its core empirical field of study (Anderson et al. 1994; Hakansson and Snehota 1989). Network theory has similarities, but can be distinguished from relationship marketing (Mattsson 1997). A network approach to markets unveils the central role of positions, links and relationships within markets (Turnbull et al. 1996).Within markets, interactive systems evolve over time as networks of networks (Iacobucci 1998).

It is within the relationships between market actors that market value is created within network. The co-creation of value is central to a modern interpretation of markets. The actors in networks are interdependent and seek to increase their importance in the network by evolving to new positions. New links and bonds with new actors increase the role of an actor in a network. The individual actor is not as creative without the bundles of network connections. It is when participants in networks come together and cocreate that valuable output is generated. This is applicable to the art market where artists as well as their art forms are dependent on galleries, auction hoses, investors, perhaps even museums and an audience in order to be appreciated as an artist.

\section{Arts Marketing: an Evolving Area of Research}

O'Reilly (2011) presents a comprehensive overview of the arts marketing literature. By mapping the territory of art related economic activity he covers areas including: arts marketing, cultural economics, creative and cultural industries, cultural policy, arts marketing management, art consumption, film, fine art, performing arts and music. Each of the divisions entail sub divisions which make up a comprehensive overview of the arts marketing area represented by more than 1500 papers. In a different review article Fillis (2011) describes the development of arts 
marketing research. He argues that: "arts marketing research has evolved from being an application of marketing using long-held principles into a discipline where critical and creative approaches are now being used to generate more meaningful and actionable arts marketing theory" (Fillis 2011).

Our empirical investigation falls within a broad definition of arts marketing and covers the marketing of very different kinds of art such as traditional and contemporary visual art, photography, opera and theater as well as the definition and the concept of art such as art schools and organizations that assess art, e.g. Carnegie Art Award. Theoretically it builds on recent developments of marketing theory and maps networks of co-creation in arts marketing. The research makes primarily an empirical contribution and investigates the relevance of network theory and the service-dominant logic in the arts marketing area, and secondary exercise a methodological tool for mapping and identifying these networks in a structured fashion. Arts marketing involve networking and interaction in evolving market networks. The mapping of networks makes it possible to analyze who is connected to each other and how and where co-production is taking place.

\section{Investment in art and Culture}

To co-produce cultural projects creates a strong linkage between a brand and consumer groups as it allows a company to build a community based on similar values (Dell'Era 2010). There has been a convergence between art and business. Notable examples from Italy and companies like illy café, Benetton and Diesel illustrate how investment in art and culture has had a positive impact in companies' image and brand. Part of this investment can take the form of art collections that are exhibited in the premises of a company (Comunian 2008). Art in all its forms has a growing importance to companies (Darsö 2005).

The art world can be visualized as a socioeconomic network which is made up of artistic and business activities, by organizations and individuals (Fillis 2009). Companies' involvement in the art industry is directed towards the creation of value for its customers by adding symbolic, esthetic and cultural significance to its products and services. The added value can be described as the company's opportunities to handle network relationships and communicate with customers. By investing in art and culture as part of a business strategy, companies can differentiate themselves from competitors in a market and create competitive advantage. This leads to new challenges for companies, to compete with creativity and esthetics (Comunian 2008).

The description of the art consumer as a producer is applicable to the art industry, and the market can, instead of being analyzed as products, be analyzed in light of the emergence of a new service dominant logic. Applying the service dominant logic, rather than the product dominant logic, makes sense in the art business. It is in the eyes of the appreciator of art that art in its different forms generates value. A market is generated when different participants in the art market interacts. Artists and the organizations and actors that supply and exhibit art such as art galleries, auction hoses, museums, collectors and art investors make it possible for an audience to appreciate art. Art is also displayed, connected to, or even intertwined with non art organizations such as lawyers' offices, banks, manufacturing companies etc to augment the service provided.

\section{The Correspondence Analysis Methodology}

The study is designed as a study of company or organization characteristics and relationships between i) the nonprofit art market and ii) ordinary profit oriented businesses as well as iii) other relationships. The study is based on prime and secondary data: telephone interviews to cover information on company art collections, and company information from internet, from printed media and also membership rolls of informal associations. Data from 2011 has been collected and analyzed with the use of multivariate correspondence analysis.

Correspondence analysis is a mathematic-statistical method that creates a geometric multidimensional room of attributes. These attributes may be whatever one as a researcher chooses to pick to describe the actors or specimen in any field of research or research purpose. In archeology it may be used to characterize ancient items found in an historic site. The specimen may in that case be e.g. ancient vases denoted with characteristics such as size, style, decoration, material, depth and position in the excavation area etc. to give various examples of attributes from this particular field of research. In consumer research the task may be to analyze consumer strategies and preferences in which demographic information (e.g. income, age, sex, ) often is combined with lifestyle and consumption preferences. In this study company attributes such as turnover, year of establishment, line of business, ownership and art collections are indicators of overall company characteristics. Board members' association or membership in social organizations and relationships with non-profit art organizations are indicators of informal relationships. The research process has firstly been to create a space or room with MCA of different company characteristics, and secondly to apply relationships to non-profit art organizations in to this room of company characteristics. In this room, opposite attributes repel actors or individuals (company attributes in this study) from each other thus forming polarities far apart in a so-called Barycentric coordinate system, while similar attributes attract actors to each other thus forming clusters of actors with similarities. The more actors have in common with one another (e.g. same category of turnover etc.) the closer they will end up in the coordinate system which theoretically can be 
interpreted as a map or a room of company characteristics and relationships or networks. Thus identical attributes produce identical positions in the coordinate system forming clusters of similar attributes or characteristics, where relationships are some of these characteristics in our study. In accordance with the aforementioned, opposite attributes produce opposite positions. Hence different clusters or polarities are produced in the space or room that the graph visualizes.

Correspondence analysis (CA), multiple correspondence analysis (MCA), and principal component analysis (PCA) are different types of multivariate analysis methods. Correspondence analysis and multiple correspondence analysis are also methods based on geometric data analysis, a visualization of data. Multivariate data analysis is a statistical method that can treat a multitude of variables simultaneously and geometric data analysis concerns the creation of a geometric space. In the Anglo-Saxon tradition, mainly represented by Greenacres (Greenacre, 1984; Greenacre, and Blasius, ed. 1994), correspondence analysis, including multiple correspondence analysis, and theory are distinctly separated. In the French tradition based on Bourdieu's works (Bourdieu 2004, 1994, 1993; Bourdieu et al. 1991), correspondence analysis is intertwined with theory, and is now represented foremost by Le Roux (Le Roux and Rouanet 2004; Lundin 2005 p. 16).

The methodological objective of geometric data analysis is nevertheless to illustrate how different variables are associated with each other by creating a number of linear relations of these variables. These linear relations are illustrated by axes created by decreasing variance. The first axis is thus generated with dataset variables that explain most of the variables' total variance.

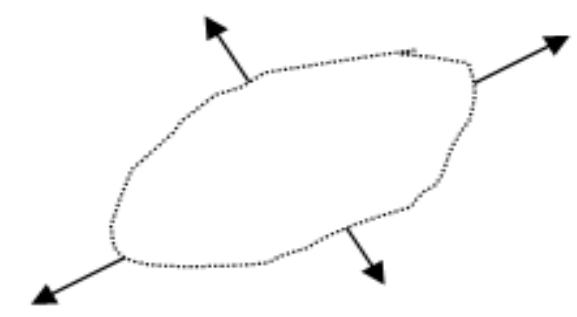

Figure 1: Data observations or categories are illustrated by the dotted line. The double arrow lines represent how the axes are formed along the cloud of data observations. The first axis is formed along the longest distance through the elliptically shaped cloud of data, the second axis along the second longest distance, the third axis along the third longest distance etc. (Green \&Tull, 1978, p. 430) Note that geometric data analysis can theoretically create an infinite number of dimensions with an equally infinite number of axes.

Next axis is generated with dataset variables that explain second highest number of variables' total variance, and so on. Since the axes measure the variance, or deviations from a mean in the empirical material, positions of the actors are created based on attributes, thereby creating e.g. clusters and polarities. The spread of the data material and the distribution of data take place around the mean, which is the absolute center of this geometric space, in correspondence analysis a so-called Barycentric coordinate system.

If empirical data would be identical, all categories would end up in the absolute middle and a meaningful coordinate system would be impossible to create.

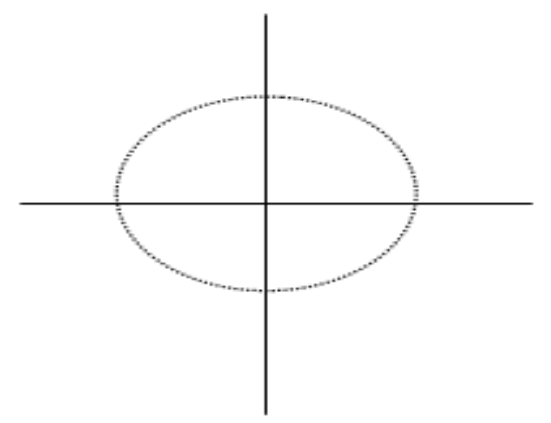

Figure 2: This figure illustrates how a data set without any correlation does not form any axes in a geometric data analysis. (Green \&Tull, 1978, p. 430)

Our aim with MCA is to use an analytical tool that in a structured manner plots a cloud of companies with their characteristics and relationships. An approach that emphasizes actors' relationships and inter-dependence is fundamental in network theory as well as in relationship marketing.

Empirical studies based on network theory or relationship marketing can be methodologically uncertain when applying an aggregated approach, if no strict methodological structure is applied.

With correspondence analysis the random elements are significantly reduced. The tool and the analysis are based on mathematical-statistical definitions and established rules of thumb. Another advantage of correspondence analysis is that it is not necessary to assume any conditions, as with traditional hypothesis-testing quantitative methods such as correlation and regression analysis or even with principal component analysis that presupposes that data is based on hierarchies. In practice this means data on at least an ordinal scale level, not a nominal scale level that correspondence analysis allows data to be of. In fact the different correspondence analysis methods allow the user to apply an explorative and inductive course of action, contrary to traditional hypothesis-testing quantitative methods as well as principal component analysis. Correspondence analysis comprises both a quantitative and a qualitative approach. The various categories, e.g. actors and their attributes, that form a mathematical coordinate system, are the initial and quantitative part of the analysis. This geometric diagram that hence has been created, whether one refers to it as room, space, industry, market, submarket or something else depending on theoretical perspective as well as empirical data, must then be interpreted, which is the qualitative part of the analysis. Correspondence analysis also stresses the importance of the visualization. An analysis of the visual graph and how variables relate to each other is an important step in the 
analysis process. (Lundin 2005 p. 8)

In this study we have chosen to identify the art market in Stockholm. We regard this market as methodologically suitable for analyzing co-creation of value in a network related structure. The categories consist of non-profit art producers and profit oriented art consumers or collectors as well as their attributes and thus their respective relationships. An important part of the analysis is that different art collectors hold different types of art. The fact that different companies hold different types of art or cooperates with different kinds of art organizations is most certainly a part of a marketing strategy or at least a choice that emanates from the corporate culture. The data is processed and analyzed using multiple correspondence analysis (MCA), thus making the best use of data of different characteristics (scale, ordinal, nominal) and also allowing an analysis of data in an exploratory manner. The geometric data space that is created from the geometric distances from the center of the Barycentric coordinate system as well as the distances between all the categories can thus be interpreted as different types of relationships, networks, contacts and inter-dependence between producers and consumers in the art market in Stockholm. It is a kind of market analysis, or expressed slightly differently a kind of network or relationship analysis limited to a specific room or space. The company characteristics make it possible to analyze how marketing differs between different kinds of companies, depending on the relationship to the art market. An early hypothesis has been that different companies develop different kinds of attitudes and partnerships or relationships to anything in relation to art. Since art collections or cooperation with art organizations is a part of a company's identity, it becomes a part of the company's communication with the market, thus a part of the marketing. This also applies for the non-profit art business. In this way value can be co-created between seemingly very different parties.

\section{The Room of Co-Creation of Value between Art Organizations and Business Companies}

The empirical data in the study is based on two main subsets. The first subset mainly refers to arts companies. Some exceptions to outright arts companies exist such as organizations dealing with education. All the organizations in this subset are however not-for-profit organizations. Examples of non-profit organizations in this first subset are galleries1, art museums, theaters, opera houses, art schools, art associations and other organizations related to the Swedish art market. The survey covers 43 not-for-profit organizations on the art market. There is a particular reason for mixing different kinds of art such as visual art,

1 Although galleries normally sell art works for profit, the non-profit galleries in this data set are a museum kind of gallery. performing art etc. and art organizations such as opera houses, theaters, galleries etc. in this study. As the hypothesis is that different art and art organizations provide different kind of value, this study tries to test what kind of art or art organization is associated to what kind of company. The second subset covers traditional profit making companies that have direct or indirect interaction or links to the art market. These profit making companies represent to a relatively large extent law firms, banks, investment banks and also companies in other sectors such as profit making galleries, auction houses and businesses in various types of production, see table1 below.

Thus the two subsets differ in that the first covers notfor-profit organizations on the art market and that the second subset covers profit making companies with some kind of connection to the art market. The second subset covers 108 commercial firms operating in different markets and with different types of connections to the art market. In analyzing the interaction between the art market and the business companies will be performed. Interaction can be explicit direct exchange or co-creation of value if you like, as in the examples of Proventus interacting directly with Magazine 3/Stockholms Art Gallery and the Jewish Theatre, Carnegie Investment bank interacting directly with the Carnegie Art Award, and Vostok Nafta AB and Bukowski Art Trading $\mathrm{AB}$ interacting directly with the Swedish Museum of Photography. Interaction can also be more subtle, personal connections or networks without explicit conscious cooperation. In our search for less pronounced collaborations, we have mapped directors that are both on the boards in business and in art organizations, or in both markets if you like. We have also mapped board members' affiliation to established networks or associations where networks can be created such as e.g. membership clubs and other kinds of closed societies.

Table 1: Line of business of the profit making companies.

\begin{tabular}{llll}
\hline & & Frequency & Percent \\
\hline Valid & Law firm & 5 & 4,6 \\
& Auction house & 7 & 6,5 \\
Gallery/Art firm & 14 & 13,0 \\
Bank & 8 & 7,4 \\
Inv. bank & 25 & 23,1 \\
& Prod./Other & 49 & 45,4 \\
Total & 108 & 100,0 \\
\hline
\end{tabular}

As regards to the limited sample of the Stockholm based companies and art organizations, this choice can be justified by the fact that a significant part of the art market has its base in the capital and that other regions or submarkets in the rest of the country need to take the Stockholm market and activities into consideration. These 
circumstances should in no way be unique for Sweden.

Please note that the distinction is made between profit and non-profit organizations. Thus some e.g. galleries can be in the category of non-profit organizations, whereas others can be in the category of profit organizations. One of the interesting points is the co-creation of value, although the different kinds of organizations create different kinds of value, one profit, the other credibility and confidence on the art scene.

In total, 14 variables were used in the final multivariate correspondence analysis, with 123 variable categories, or modalities that the variable categories are sometimes called in correspondence analysis. After examining the variables and their inter-relationships, we have created a room of cocreation of value, consisting of 8 active variables of 30 variable categories and seven illustrative, inactive or supplementary variables of 76 variable categories, see figure 3 below. The active variables consists of data of the profit-making companies such as turnover, line of business, year of establishment, ownership, board composition, and membership in clubs. The variable membership in clubs is measured with four variable categories. The seven illustrative variables measure direct and indirect links to specific arts organizations ( 7 variables), board composition, prominent person as board member, and also corporate art holdings (see Appendix). 2

According to the alboge criterion or the scree plot principle (Hjellbrekke 1999, p 38) the room produced by the correspondence analysis provides us with information that only the three first axes should be included in further analysis, see Appendix for each axis' relative contribution. The three axes produced are called axis 1 (horizontal), axis 2 (vertical) and axis 3 (vertical). After that the correspondence analysis has produced a geometric room based on numerical distances of the variable categories to the center of the graph (barycenter), the next step is to interpret what the axes measure.

Axis 1 is determined by a polarity between large versus small turnover, old companies versus newly established, membership for board members to a club versus no membership and family owner versus private owner. Other variable categories that determine the axis are investment bank and financial family, both these categories on the same side of the graph oriented towards the polarity of large companies (-). The before mentioned polarities can be found in opposite parts of the graph. The old companies with high turnover are oriented towards the top left corner of the graph $(-,+)$ and also somewhat around the 0-point of axis $2(-, 0)$. The opposite type of business is oriented towards the upper right of the graph $(+,+)$ and also around the 0 -point of axis $2(+, 0)$. This is clearly shown in graph 1 above. The structure that large turnover is oriented in the same polarity as early year of establishment seems perfectly natural.

Axis 2 is determined by large and medium-old

\footnotetext{
${ }^{2}$ In data processing Excel, SPSS (IBM) and SPAD (Decisia) were used.
}

companies, if one is to slightly simplify the interpretation of the impact of the variable categorization of the axis. In addition, line of business (auction companies and other companies), public owner and board composition (celebrity versus no celebrity, no financial family) produce the axis. The most obvious pattern is that club membership of Club $\mathrm{B}$ and public owner are oriented towards the part of the graph in which companies with large turnover etc. are $(-,+)$, versus club membership of Club A (the less exclusive club), no financial family on the board are oriented towards the part of the graph where mid-sized companies can be found $(-,-)$. It is worth pointing out that in the same particular area of the graph where large and old companies $(-,+)$ are also variable categories club membership in Club $\mathrm{B}$, an exclusive club with only about 300 members $(-,+)$. The other variable category of club $\mathrm{A}$, is on the other hand more oriented towards medium-sized companies (-,-). The variable category no club membership is clearly oriented to the part of the graph where the small companies can be found $(+, 0)$. This appears perfectly natural.

Axis 3 is determined by a polarity between those companies with mid-size turnover versus small, although this polarity constituting axis 3 is not as clear as for axis 1 . In addition, the axis is determined by a polarity between owners (public owner versus family owner) and person on the board (no financial family versus financial family, nobility versus no nobility).

A summary and simplification of the interpretation of the axes is that Axis 1 measures the size and year of establishment for the profit making companies, Axis 2 measures the line of business (auction house, other company)and board composition, and Axis 3 measures owner and board composition. Thus axis 1 measures the size of the companies, while axis 2 and 3 divide the companies into more detailed information: line of business and, board composition and owner category.

In the first interpretation of the graph, we have so far made an understanding of the structure of the room of cocreation of value. In the next interpretation phase, we analyze the structure of the art organizations with respect to the profit making companies. We thus analyze the distribution of the illustrative variable categories in the graph, as we now know the structure of the room.

Art organizations, or the illustrative variable categories (illustrative modalities), are distributed in relationship to the room of co-creation of value so that direct link between companies and art organizations constitutes an orientation of Sven Harry's Art Museum, Carnegie Art Award and Magazine 3 / Stockholm's Art Hall towards large companies in the graph $(-,+)$, while the Museum of Photography and Artipelag are oriented towards small and mid-sized companies, see graph 2 below. The structure of direct link between businesses and arts organizations are also confirmed by the variables measuring association between profit making companies and arts organizations. Carnegie Art Award and Opera Initiative are oriented towards large companies and Museum of Photography is 
oriented towards small companies.

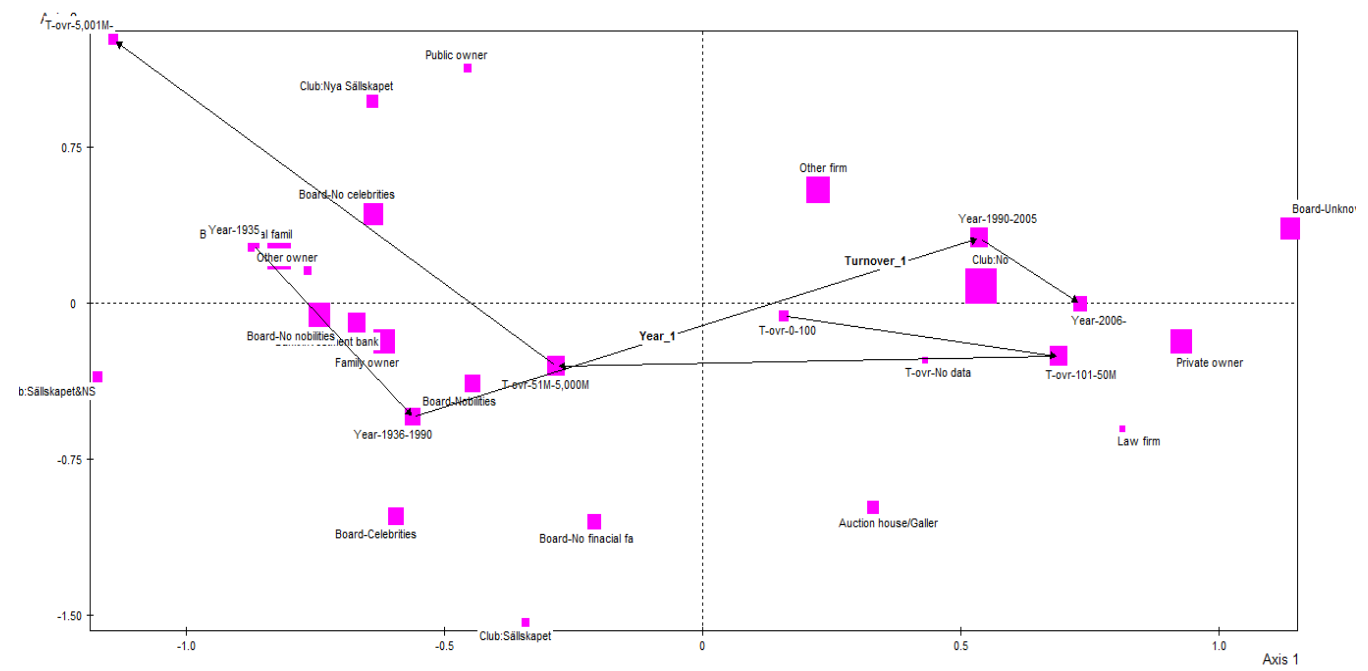

Figure 3: A visualization of the room of co-creation of value showing some attributes of the profit making business companies, active variable categories (modalities). To clarify the structure of the room the variable categories of turnover and age of the companies have been linked together with arrows. Please note that young companies with low turnover are oriented to the right side of the graph $(+, 0)$, and the opposite kind of companies to the top left corner $(-,+)$.

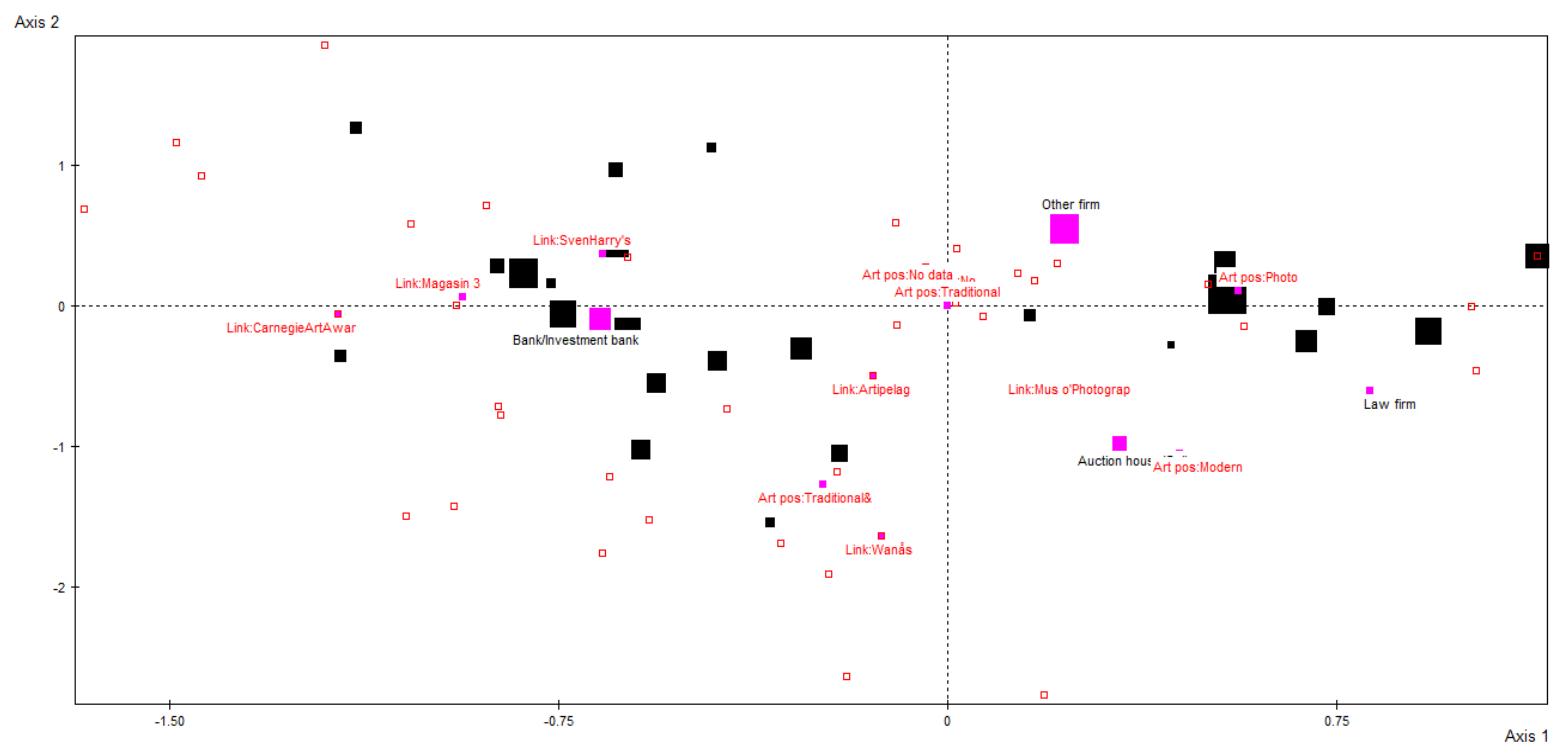

Figure 4: A visualization of the room of co-creation of value showing some attributes (inactive modalities) of the not for profit art organizations, showing that Carnegie Art Award, Magasin 3/Stockholm Art Hall and Sven Harry's Art Museum are oriented towards large companies, traditional and modern art possessions are oriented towards mid-size companies and Museum of Photography as well as photo as art possessions are oriented towards small companies.

The profit making companies which actively act on the art market (auction houses and galleries) are somewhat oriented towards the Museum of Photography, which to a great extent can be explained by the auction house Bukowski, with its direct link and cooperation with the Museum of Photography. In a similar position as the category "auction house and gallery" is the category "law firm". The category "other firm" (production or other line of business) are oriented towards small companies in the graph. Finally corporate companies' art possessions consists of photography, which is oriented toward the polarity of the small companies $(+,+)$, possessions of traditional art is oriented towards the middle of the graph, i.e. Barycenter, which means that this kind of art possession does not belong to companies that are extreme in the data material in any way, or expressed differently: it is a mainstream possession. Modern art possessions as well as possessions of both modern and traditional art are oriented to medium-sized companies.

To summarize, the room of co-creation of value between the Swedish not-for-profit art organizations and the profit making companies, the first conclusion is that the attributes of the companies (size, constitution of the board, line of business) are important for connections in the art market, 
whether they are mainly developed and chosen by the commercial companies themselves, by the arts organizations, or by both in collaboration. The more detailed nature of the relationships we have no knowledge of in this study. Newly established companies with low turnover are oriented towards photography. More established companies (mid-sized companies) are oriented towards both traditional and modern art possessions and also associated with photography as an art form, such as the Swedish Museum of Photography. The large and established companies consist of categories like "investment banks" are "Carnegie Art Award". This award can be regarded as a strategy for e.g. the investment bank Carnegie to participate in the legitimization of art. This relatively large and more than 200 year old investment bank has direct links to and power over the Carnegie Art Award. Possibly, one could define three polarities of the room of co-creation of value. One part is associated with the art market in a strategy to define art (e.g. Carnegie), one part is associated with art possessions that are relatively traditional, i.e. traditional and modern art possessions, the third part are small companies that have applied a strategy to place photography as a fully legitimate art form among the more traditional arts. In that perspective the smaller companies associated with photography can be seen as challengers of the definition of art. The establishment of photography as a relatively new art form enjoy however some significant resources from some significant companies (the auction house Bukowski and the oil conglomerate Vostok Nafta). The legitimization of what the market should regard as art can one side successfully be handled through an institutionalization of the art form, as the example of Carnegie and the Carnegie Art Award for modern yet traditional art, and on the other hand the Swedish Museum of Photography which aim to launch and establish a new art form. Photography, as a less expensive form of art possession is also oriented towards small companies, one might stress.

A dependence on strong owner families becomes apparent in the room of co-creation of value in variable categories such as board composition and dominant owner families. These categories are mainly oriented towards the polarity that is characterized by large companies. A heterogeneous board composition is oriented towards the large company polarity.

A systematic way to analyze the material and its polarities is to conduct a cluster analysis. The principle behind this analysis is to find characteristics of the companies for a predetermined number of subsets. Groups range from the data set as one sub-group only to sub-groups with fully equivalent characteristics. If the material into subsets would be divided into sub-groups of identical characteristics, the number of subsets would naturally become very large, and in many cases, these sub-groups would consist of only one company. The cluster analysis that is displayed below confirms the earlier correspondence analysis.

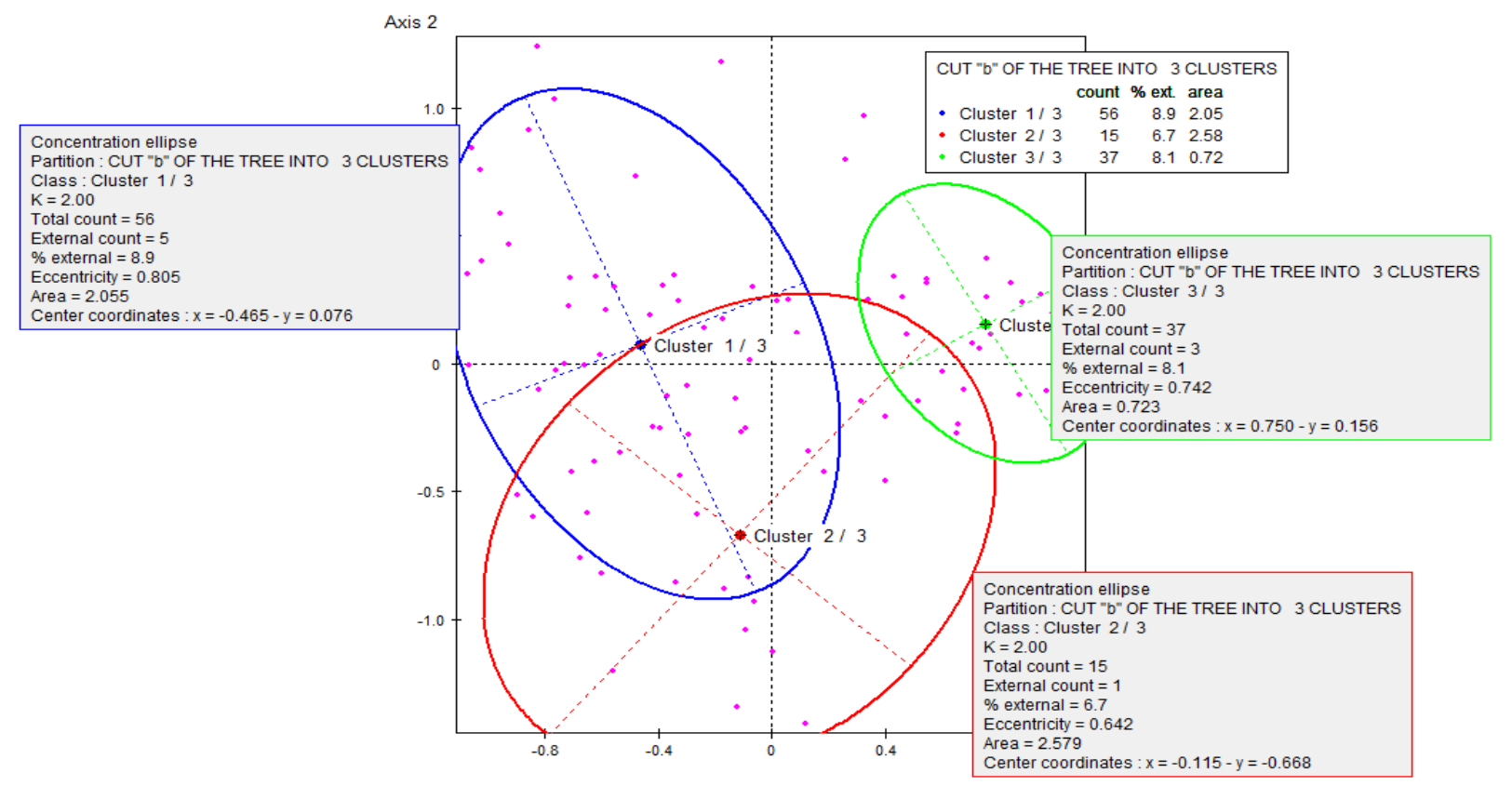

Figure 5: A visualization of the cluster analysis of three clusters, where only some of the characteristics of the clusters are mentioned: 1: bank/investment bank, member from established financial family on the board, dominant family owner, high turnover, person on the board belonging to Club A and/or Club B 2: medium turnover, person on the board belonging to club A, 3: unknown board members, private owner, person on the board belonging to no club.

\section{Conclusions}

Arts marketing is analyzed with reference to the Service
Dominant Logic in marketing. Relationships are regarded as conceptually and principally similar to networks. Relationships are however more of a dual or possibly a 
limited number of external company connections, whereas networks are regarded as multiple, web like external connections. Data is mainly collected from the non-profit art market in Stockholm as well as the profit oriented businesses that cooperate or are associated to this art market. Data stems from 2011 and although the study does not claim to be a complete and full coverage of the art market, it nonetheless covers many of the major non-profit art organizations. The collaborations or connections between traditional business and the art market are made generally known to clients, customers and the public, on the company web page and through company reports. The same applies for the non-profit art organizations. Corporate art collections are exposed in places that are open to customers and clients. Thus the relationships or collections are made public and are ways of co-creating values.

Arts marketing can be enhanced by emphasizing the service provided by key art relationships consisting of public and private nonprofit art organizations, thus creating value for both parties although one is profit oriented and the other is not. The principal implications of this study are probably valid also on other markets outside Sweden. However, marketing and value creation would most likely be more nuanced in larger markets with more companies and more cultural expressions, cultural organizations and traditional businesses such as on the art scene in Berlin, London, Paris and New York.

The research is a novel approach to arts marketing and maps relationships where the value of art as well as company marketing is co-created by different participants mainly between the nonprofit art business and traditional profit oriented companies. The use of multiple correspondence analysis enables a production of a visual space of relationships and its characteristics. This space can be regarded as a sort of cluster analysis with different polarities that divide and unite in accordance with the position in the MCA-space. Within polarities characteristics and relationships are similar, and the opposite between different polarities.

Art organizations that produce, supply, exhibit and define art are surrounded by relationships or networks that appreciate art, are willing to participate in the art market, and are willing to pay for art. The different actors that appreciate art, invest in art, handle or manage art coproduce the service which art is representing. The different relationships in the art business can be analyzed in a structured way with the multiple correspondence analysis method. The correspondence analysis creates a limited room or a space of what is being studied, in this case a room of businesses with its characteristics and their relationships with art and the art market, i.e. of relations and interrelations between the different organizations on the non-profit art market and these organizations' connections to profit oriented, non-art businesses. After having analyzed this room of business characteristics and relationships and establishing what variables the room is created from a structure can be identified. The main conclusion from this structure is that large companies with a multitude of well-known business and art people as well as well-known families in the companies or associated to them were opposite to small companies without that multitude of established people or families associated to these smaller companies. This conclusion could be identified in three different polarities or clusters in three different parts of the room of networks (figures 3, 4 and 5).

The art market is linked to the business companies in the way that more established art forms that define relatively traditional visual art as Carnegie Art Award are oriented towards the polarity of the large business companies, whereas new art forms such as photography is oriented towards the polarity of the smaller companies. The smaller companies associated with photography can be seen as challengers of the traditional definition of art. So far and within certain circles photography can still be viewed with some doubts as to whether it is a proper art form or not. A striking condition in the data material is the presence of dominant owner families. These families are likely to be a prerequisite for a profit making company to venture into the art market. Photography, as a less expensive form of art possessions, are oriented towards small companies, which could be explained by the more scarce resources associated with small companies and thus considerable limitations to invest in art, while the large companies have enough potential to invest in the full spectrum of the art market. The large investment bank Carnegie has for example a wide spectrum of art possessions in their offices, ranging from traditional oil paintings in gold frames from the 1800's to new and contemporary art. A strategy of marketing the company itself as well as Carnegie Art Award is to exhibit the candidates for the prizes in the premises exposed to the bank clients. A structure in the room is that strong and established owner families is associated to established art forms and to a certain extent also associated with traditional art possessions. This association is probably due to the fact that an involvement in the art market is a longterm commitment dependent on a strong family ownership and also recognition that involvements in art must emerge gradually. Investments in art possessions and in art organizations are not directly related to the profit making companies' own operations. An engagement of that kind can mean major measurement difficulties relating to the actual usefulness as well as great financial risks. Perhaps that kind of involvements must go on for decades, and also marked by personal art interests of a strong owner family.

Some businesses have created their own or even in house art activities or art organizations and thus made specific large investments of both capital and commitment on the art market. The most obvious examples of this are Carnegie with its Carnegie Art Award, Proventus with its Jewish theater and Bukowski with its Museum of Photography. However, they differ slightly in the intentions or use of the relations. Neither Carnegie nor Proventus receive any direct tangible gains of cooperation other than reputation, while on the other hand Bukowski indirectly can promote 
photography through the Museum of Photography. As this relatively new art form has become accepted and legitimate, it can then be sold via Bukowski. The "large investors" on the art market are in contrast to the businesses that are "small investors": the ones that choose to collect and exhibit photography. This art form usually involves no large investment, and implies no risk of great loss or, for that matter, no great chance of success.

Our study shows that it is not uncommon for traditional profit oriented companies to have different types of engagement and activity on the art market. One of the conclusions is that a business can get involved on the art market in some way as part of a marketing plan. In what way and to what extent the company must determine, probably depending on the existing corporate culture. Even from the art organizations' perspective relationships with companies can be beneficial. Art organizations enjoy financial benefits and are made more widely known and in exchange they share their reputation and are made a part of a marketing plan. However, there is most probably a fine line between how much the parties can get involved in the other party's world. The art market cannot degenerate artistic values with too much economic orientation, just like the business world must keep focus on their core business.

Art can be viewed as a service in line with the new service dominant logic within marketing. By quantitatively analyzing the different networks we have made contributions to research within arts marketing by applying what has been known as the Nordic school of marketing. Geometric data analysis with e.g. multivariate correspondence analysis is particularly useful as a methodology to study networks. Network theory is applicable to illustrate how co-production takes place within market relationships. Network theory contributes thereby to the advancement of the service dominant logic within marketing. Art is appreciated as a service and is promoted through networks of actors within the art business. Art can enhance the service encounter and be used to augment the brand of a product or a company. It is within networks of art appreciation that art is given a value. The strength or weakness of network connections can explain the vast differences in price or market value that different pieces and forms of art are representing.

There are a number of interesting areas for further research. One would be to study the larger art markets with also more traditional companies established. The larger markets would provide more opportunities for relationships between the art market and traditional businesses, such as Berlin, London, Paris and New York. Another possible area for further research would be to study differences between countries or cultural spheres. One advantage of studying the larger markets would be that with more cultural manifestations and thus more options for different types of relationships any nuances would most likely become more apparent, i.e. unique marketing values.

\section{Appendix}

\section{Contribution to the axis}

\begin{tabular}{|c|c|c|c|}
\hline Label & Axis 1 & Axis 2 & Axis 3 \\
\hline \multicolumn{4}{|l|}{ Club_1 } \\
\hline Club:No & 5,10 & 0,19 & 0,59 \\
\hline Club: A & 0,36 & 11,67 & 3,25 \\
\hline Club: B & 2,04 & 7,56 & 1,22 \\
\hline Club:A.\& B. & 6,10 & 0,91 & 1,29 \\
\hline TOTAL & 13,61 & 20,33 & 6,35 \\
\hline \multicolumn{4}{|l|}{ Turnover_1 } \\
\hline T-ovr-0-100 & 0,12 & 0,03 & 6,16 \\
\hline T-ovr-101-50M & 4,64 & 0,99 & 0,63 \\
\hline T-ovr-51M-5,000M & 0,76 & 1,39 & 9,46 \\
\hline T-ovr-5,001M- & 6,15 & 12,21 & 0,27 \\
\hline TOTAL & 11,67 & 14,62 & 16,53 \\
\hline \multicolumn{4}{|l|}{ Year_1 } \\
\hline Year-1935 & 4,40 & 0,74 & 0,03 \\
\hline Year-1936-1990 & 2,62 & 4,04 & 0,09 \\
\hline Year-1990-2005 & 2,71 & 1,50 & 6,10 \\
\hline Year-2006- & 3,42 & 0,00 & 6,20 \\
\hline TOTAL & 13,15 & 6,29 & 12,42 \\
\hline \multicolumn{4}{|l|}{ Business_1 } \\
\hline Lawfirm & 0,92 & 0,81 & 2,23 \\
\hline Auction house/Galler & 0,64 & 9,04 & 4,48 \\
\hline Bank/Investment bank & 4,11 & 0,13 & 0,72 \\
\hline Otherfirm & 0,69 & 6,50 & 0,04 \\
\hline TOTAL & 6,36 & 16,48 & 7,48 \\
\hline \multicolumn{4}{|l|}{ Owner_1 } \\
\hline Private owner & 10,27 & 0,66 & 0,01 \\
\hline Public owner & 0,69 & 6,85 & 19,99 \\
\hline Familyowner & 4,32 & 0,61 & 5,30 \\
\hline Otherowner & 1,95 & 0,13 & 0,00 \\
\hline TOTAL & 17,23 & 8,25 & 25,31 \\
\hline \multicolumn{4}{|l|}{ Board_Cel } \\
\hline Board-Unknown & 13,68 & 2,16 & 0,02 \\
\hline Board-No celebrities & 4,51 & 3,29 & 0,15 \\
\hline Board-Celebrities & 2,93 & 14,06 & 0,08 \\
\hline TOTAL & 21,12 & 19,51 & 0,26 \\
\hline Board_Fin & & & \\
\hline
\end{tabular}




\begin{tabular}{llll}
\hline Board-No finacial fa & 0,28 & $\mathbf{1 1 , 4 1}$ & $\mathbf{1 1 , 1 2}$ \\
Board-Finacialfamil & $\mathbf{8 , 7 5}$ & 1,09 & $\mathbf{4 , 8 7}$ \\
TOTAL & 9,03 & 12,50 & 15,99 \\
Board_Nob & & & \\
Board-No nobilities & $\mathbf{6 , 2 5}$ & 0,06 & $\mathbf{6 , 0 9}$ \\
Board-Nobilities & 1,59 & 1,96 & $\mathbf{9 , 5 8}$ \\
TOTAL & 7,84 & 2,02 & 15,66 \\
\hline
\end{tabular}

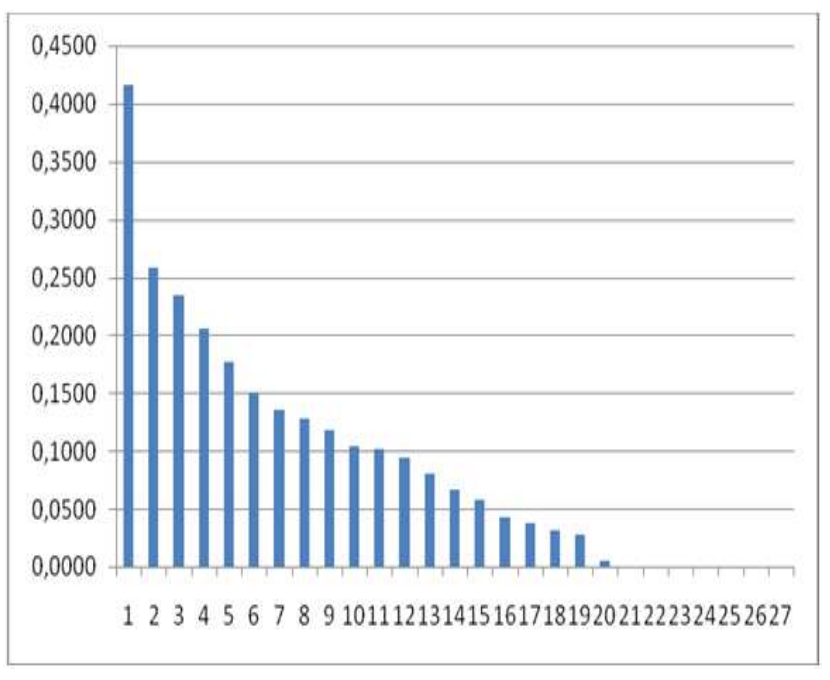

\begin{tabular}{|c|c|c|}
\hline \multicolumn{3}{|c|}{$\begin{array}{l}\text { Characterisation by categories of groups of } \\
\text { CUT "b" OF THE TREE INTO } 3 \text { CLUSTERS } \\
\text { Group: Cluster } 1 \text { / } 3 \text { (Count: } 56 \text { - Percentage: 51.85) }\end{array}$} \\
\hline & Caracteristiccategories & Histogram \\
\hline Board_Fin & Board-Finacialfamil & $* * * * * * * * * * * * * * * * * * * * * * * * * * * * * *$ \\
\hline Owner_1 & Familyowner & $* * * * * * * * * * * * * * * * * * * * * * *$ \\
\hline Board_Cel & Board-No celebrities & $* * * * * * * * * * * * * * * * * * * * *$ \\
\hline Board_Nob & Board-No nobilities & $* * * * * * * * * * * * * * * * * *$ \\
\hline Board & Brd:Fin. family & $* * * * * * * * * * * * * * * *$ \\
\hline Turnover_1 & T-ovr-5,001M- & $* * * * * * * * * * * * * * *$ \\
\hline Business_1 & Bank/Investment bank & $* * * * * * * * * * * * * * *$ \\
\hline Club_1 & Club: A \& B & $* * * * * * * * * * * * * *$ \\
\hline Board_Nob & Board-Nobilities & $* * * * * * * * * * *$ \\
\hline Board & Brd:Fin.\&Nob. & $* * * * * * * * * *$ \\
\hline Year_1 & Year-1936-1990 & $* * * * * * * * * *$ \\
\hline ProminentBoard & Brd:Storch & $* * * * * * * * *$ \\
\hline Board & Brd:Cel.\&Fin. & $* * * * * * * * *$ \\
\hline Board_Cel & Board-Celebrities & $* * * * * * * *$ \\
\hline Artposes & Art pos:No data & $* * * * * * * *$ \\
\hline Owner_1 & Public owner & $* * * * * * * *$ \\
\hline Group: Cluster 2 / 3 (Count: & 15 - Percentage: 13.89) & \\
\hline Variablelabel & Caracteristiccategories & Histogram \\
\hline Club_1 & Club: A & $* * * * * * * * * * * * * * * * * * * * * * * * *$ \\
\hline Turnover_1 & T-ovr-51M-5,000M & $* * * * * * * * * * * * *$ \\
\hline Board_Fin & Board-No finacial fa & $* * * * * * * * * * * * *$ \\
\hline Business_1 & Lawfirm & $* * * * * * * * * * * * *$ \\
\hline Board & Brd:Cel./Kno & $* * * * * * * * * * *$ \\
\hline Board_Cel & Board-Celebrities & $* * * * * * * * * *$ \\
\hline Year_1 & Year-1935 & $* * * * * * * * *$ \\
\hline Artposes & Art pos:Traditional\& & $* * * * * * * * *$ \\
\hline Group: Cluster 3 / 3 (Count: & 37 - Percentage: 34.26) & \\
\hline
\end{tabular}




\begin{tabular}{lll}
\hline Variablelabel & Caracteristiccategories & Histogram \\
Board & Brd:Unknown & $* * * * * * * * * * * * * * * * * * * * * * * * * * * * * * * * * *$ \\
Board_Fin & Board-Unknown & $* * * * * * * * * * * * * * * * * * * * * * * * * * * * * * * * * *$ \\
Board_Cel & Board-Unknown & $* * * * * * * * * * * * * * * * * * * * * * * * * * * * * * * * * * *$ \\
Board_Nob & Board-Unknown & $* * * * * * * * * * * * * * * * * * * * * * * * * * * * * * * * * * *$ \\
Owner_1 & Private owner & $* * * * * * * * * * * * * * * * * * * * * * * *$ \\
Club_1 & Club:No & $* * * * * * * * * * * * * * * * * * * *$ \\
ProminentBoard & Brd:Unknown & $* * * * * * * * * * * * * * * * *$ \\
Year_1 & Year-1990-2005 & $* * * * * * * * * * * * *$ \\
Turnover_1 & T-ovr-101-50M & $* * * * * * * * * * * * *$ \\
Year_1 & Year-2006- & $* * * * * * * * * * * * *$ \\
Link_Art_org_1 & Ass:Swed Mus o'Photo & $* * * * * * * * * * *$ \\
Link_Art_org_2 & Ass:No & $* * * * * * * * * *$ \\
Business_1 & Otherfirm & $* * * * * * * * *$ \\
\hline
\end{tabular}

\section{Acknowledgements}

We wish to thank Lina Östlund for her practical contribution to the gathering of data and her involvement in some of the discussion of the findings.

\section{References}

[1] Anderson, J.-C,: Hakansson, H. and Johanson J. (1994), Dyadic business relationships within a business network context, Journal of Marketing, Vol. 58, No. 4, pp. 1-15

[2] Arnould, E. J. and Thompson, C. J. (2005), Consumer cultural theory (CCT): Twenty years of research, Journal of Consumer Research, Vol. 31, pp. 29-32

[3] Ballantyne: D. andVarey, R. J.(2008), The service-dominant logic and the future of marketing, Journal of the Academy of Marketing Science, Vol. 36, pp. 11-14

[4] Batt, P.J. and Purchase,S. (2004), Managing collaboration within networks and relationships: Industrial Marketing Management, Vol. 22, pp. 169-174.

[5] Borg, E.A. (1991), Problem shifts and market research: the role of networks in business relationships, Scandinavian Journal of Management, Vol. 7, No. 4, pp. 285-295.

[6] Borg, E.A. (2001), Knowledge, information and intellectual property: implications for marketing relationships, Technovation, The International Journal for Innovation and Entrepreneurship, Vol. 21, No. 8, pp. 515-524.

[7] Borg, E. A. (2009): The marketing of innovations in hightechnology companies: A network approach, European Journal of Marketing, Vol. 43,No. 3/4, pp. 364-370

[8] Bourdieu, P. (1994), Praktiskt förnuft: Bidrag till en handlingsteori, Daidalos, Göteborg

[9] Bourdieu, P. (1993), Critical Perspectives, (ed.) Calhoun, C., LiPuma, E., Postone, M., Polity Press, Cambridge
[10] Bourdieu, P., Chamboredon, J.-C., Passeron, J.-C. (1991), The Craft of Sociology: Epistemological Preliminaries, (ed.) Beate Krais, Walter de Gruyter, Berlin

[11] Bourdieu, P. (2004), La distinction- Distinction: A social Critique of the Judgement of Taste, translated by R. Nice, Routledge\&Kegan Paul. London

[12] Broady, D. (1988), Jean-Paul Benzécri och korrespondensanalyse, Universitets- och högskoleämbetet, forskning och utveckling för högskolan, arbetsrapport

[13] Carn, N. et al. (1988), Real Estate Market Analysis: Techniques and Applications, Prentice Hall, Englewood Cliffs, New Jersey, USA

[14] Comunian, R. (2008), Culture Italian style: Business and the arts, Journal of Business Strategy, Vol. 29, No. 3, pp. 37-44

[15] Darsö, L. (2005), International opportunities for artful learning, Journal of Business Strategy, Vol. 26, No. 3/4, pp. 58-61

[16] Dell'Era, C. (2010), Art for business: Creating competitive advantage through cultural projects, Industry and Innovation, Vol. 17, No. 1, pp. 71-89

[17] Fillis, I. (2009), An evaluation of artistic influences on marketing theory and practice, Marketing Intelligence \& Planning, Vol. 27, No. 6, pp. 753-774

[18] Fillis, I. (2011), Theevolution and development of arts marketing research, Arts Marketing, An International Journal, Vol. 1, No. 1, pp. 11-25

[19] Gummesson, E. (2008), Extending the service-dominant logic: from customer centricity to balanced centricity, Journal of the Academy of Marketing Science, Vol. 36, pp. $15-17$

[20] Green, P.: Tull, D. (1978), Research for Marketing Decisions, Prentice-Hall international series in management, New Jersey, USA

[21] Greenacre, M. J. (1984), Theory and application of correspondence analysis, London : Academic Press 
[22] Greenacre, M. J.and Blasius, J., ed. (1994), Correspondence Analysis in the Social Sciences Recent Developments and Applications, London Academic Press

[23] Hakansson, H. and Snehota, I. (1989), "No business is an island: the network concept of business strategy", Scandinavian Journal of Management, Vol. 4, No. 3, pp. 187-200.

[24] Hjellbrekke, J. (1999), Innföring i korrespondanseanalyse, Fagbokforlaget Vigmostad \& Björke AS, Norway

[25] Hunt, S. D. (2010), Marketing Theory, foundations, controversy, strategy, resource-advantage theory, Armonk, New York: ME Sharpe.

[26] Iacobucci, D. (1998), "Interactive marketing and the meganet: networks of networks", Journal of Interactive Marketing, Vol. 12 No. 1, pp. 5-16.

[27] Le Roux, B., Rouanet, H. (2004), Geometric Data Analysis: From Correspondence Analysis to Structured Data Analysis, Kluwer Academic Publishers, Dordrecht

[28] Lundin, S. (2003), "Underlag inför seminarium om skillnaden mellan det Franska och det Angloamerikanska förhållningssättet till korrespondensanalys", framlagt vid tredagarsseminarium om korrespondensanalys i Uppsala 2-4 december

[29] Lundin, S. (2005), "Korrespondensanalys, Rapportering från en kurs", ESEP, Ethos in Society, Education and Practices, Rapport 4, Uppsala universitet

[30] Lusch R. F. and Vargo, S. L.(2006), The service-dominant logic of marketing. Dialog, debate, and directions, Armonk, New York: M.E. Sharpe

[31] Mattsson, L.G. (1997), "Relationship marketing and the 'market-as-networks' approach: a comparative analysis of two evolving streams of research", Journal of Marketing Management, Vol. 13, No. 5, pp. 447-461.
[32] Mattsson, L-G, and Johanson, J. (2006), Discovering market networks, European Journal of Marketing, Vol. 40,No. 3/4, pp. $259-274$

[33] Mitchell, C. and Imrie, B. C. (2011), Consumer tribes: membership, consumption and building loyalty, Asia Pacific Journal of Marketing and Logistics, Vol. 23, No. 1, pp. 3956

[34] O'Reilley, D. (2011), Mapping the arts marketing literature, Arts Marketing, An International Journal, 1, No. 1, pp. 2638

[35] Pärna, K., (1993), Correspondence Analysis:An Introduction and Some Examples, Research Report, Department of Statsitics, Stockholm University

[36] Rao, P.M.: Borg, E. A. and Klein, J. A. (2008), The ICT and enforcement of intellectual property rights: A relationship perspective, The Journal of World Intellectual Property, Vol. 11, No. 2, pp. 105-119

[37] Sheth, J.N.: Gardner ,D. M. and Garrett,D. E. (1988), Marketing Theory, evolution and evaluation, New York: John Wiley \& Sons

[38] Turnbull, P.: Ford, D. and Cunningham, M. (1996), "Interaction, relationships and networks in business markets: an evolving perspective", Journal of Business and Industrial Marketing, Vol. 11, No. 3-4, pp. 44-62.

[39] Vargo, S. L. and Lusch, R. F. (2004), Evolving to a new dominant logic for marketing, Journal of Marketing,Vol. 68, (January), pp. 1-17

[40] Vargo, S. L. and Lusch, R. F. (2008) Service-dominant logic: continuing the evolution, Journal of the Academy of Marketing Science, Vol. 36, pp. 1-10

[41] Östlund, L. (2011), Artwork: without title, text on paper The importance of art to the business community, Södertörn University: Honors Thesis 